\title{
Simple solvothermal approach to highly nanostructured hematite thin films
}

\author{
Casey M. Platnich, ${ }^{1, \text { a) }}$ Jachym S. Slaby, ${ }^{1}$ David O'Connell, ${ }^{1}$ and Simon Trudel $^{1,}$ b) \\ Department of Chemistry and Institute for Quantum Science and Technology, University of Calgary, 2500 University Dr NW, \\ Calgary, AB Canada T2N 1 N4
}

(Dated: 24 July 2020)

In this work, we present a solvothermal method for the synthesis of hematite thin films on fluorine-doped tin oxide substrates. This simple method uses a precursor solution of iron(III) 2,4-pentanedionate dissolved in ethanol with a microliter-scale amount of water and yields hematite $\sim 500$-nm thick films after annealing. The synthesised films were characterised using an array of methods, including scanning electron microscopy, energy-dispersive X-ray spectroscopy, diffuse reflectance, and powder x-ray diffraction. Incorporating water into the precursor solution provides nucleation sites for the reaction and results show that by altering the amount of water used in the synthesis, it is possible to generate nanocrystalline films of different morphologies, nanocrystal size distributions, and surface areas. This synthetic procedure therefore provides control over the films' physical and electrochemical characteristics. Doping of hematite thin films is also possible using this synthesis, as exemplified by doping with tin by adding tin(II) 2,4pentanedionate to the precursor solution. To demonstrate utility, we build prototype photoelectrochemical cells using the synthesized hemtatite as the photoanode.

\section{INTRODUCTION}

Nanostructured architectures are often desired for applications involving surface-mediated events, such as sensing, ${ }^{1-3}$ energy conversion and storage devices, ${ }^{4,5}$ and catalysis. ${ }^{6-8}$ Several approaches - such as templating 9,10 or the selfassembly of predefined molecular building blocks ${ }^{11,12}$ - can be taken to achieve materials with high surface areas. Methods capable of directly accessing high-surface nanostructured architectures on a substrate are desirable from scalability, simplicity, and processability points of view. Hematite $\left(\alpha-\mathrm{Fe}_{2} \mathrm{O}_{3}\right)$ is attracting attention as a water-splitting photoanode material due to its high natural abundance and low cost, nontoxicity, and stability in aqueous solutions. ${ }^{13}$ One such application of hematite benefiting from such advantages is photoelectrochemical water-splitting. ${ }^{14,15}$ Hematite as a photoanode material possesses intrinsic limitations such as poor electrical conduction. Highly structured $\alpha-\mathrm{Fe}_{2} \mathrm{O}_{3}$ photoanodes that bring the site of the $\mathrm{e}^{-}-h^{+}$pair formation close to the semiconductor-liquid junction can however efficiently allow water to be oxidized. ${ }^{13}$

Nanostructured $\alpha-\mathrm{Fe}_{2} \mathrm{O}_{3}$ films have been produced by atmospheric-pressure chemical vapor deposition (APCVD). ${ }^{16}$ Although APCVD is an effective method to form $\alpha-\mathrm{Fe}_{2} \mathrm{O}_{3}$ thin films, it requires high reaction temperatures and specialised equipment, making it an expensive procedure to scale up. Other methods for producing nanostructured $\alpha-\mathrm{Fe}_{2} \mathrm{O}_{3}$ thin films include sputtering, ${ }^{17}$ electrodeposition, ${ }^{18}$ reactive ballistic deposition, ${ }^{19}$ atomic-layer deposition, ${ }^{20}$ and sol-gel ${ }^{21}$ techniques, all of which require several reaction steps and substantial equipment, again imposing capital cost and practical limitations towards large-scale production.

\footnotetext{
a) now at Department of Chemistry, McGill Univerasity, 801 Sherbrooke St. W, Montréal, QC, Canada H3A 0B8

b) Electronic mail: trudels@ucalgary.ca
}

In this work, inspired by a report from Cai and colleagues ${ }^{22}$ who synthesised mesocrystalline hematite nanoplates in solution, we present a simple solvothermal method for the preparation of highly structured nanocrystalline hematite thin films on fluorine-doped tin oxide using an ethanol-based solution of iron(III) 2,4-pentadionate $\left(\mathrm{Fe}(\mathrm{acac})_{3}\right)$ as the precursor. Solvothermal synthetic approaches benefit from scalability and simplicity ${ }^{23,24}$ and have been extensively used to form free-standing nanostructures such as nanoparticles and nanorods. However, the application of solvothermal methods to the formation of metal-oxide thin films is still sporadic, with $\mathrm{ZnO},{ }^{25} \mathrm{WO}_{3},{ }^{26} \mathrm{BiFeO}_{3}{ }^{27}$ being examples, noting that in all of these cases water was used as the solvent (i.e. they were hydrothermal syntheses). In addition to demonstrating solvothermal $\alpha-\mathrm{Fe}_{2} \mathrm{O}_{3}$ thin-film formation, we demonstrate size control by varying the amount of water (microliter scale) added to the precursor solution, thereby regulating nucleation and growth, lending greater control over the morphologies of the produced films and an ability to tune the electrochemical properties.

\section{METHODS}

Materials. All chemicals were used as received from Sigma Aldrich or VWR unless otherwise indicated, without additional purification or modification. Ultrapure water with a resistivity of at least $18 \mathrm{M} \Omega \mathrm{cm}^{-1}$ was produced using a Barnstead Ultrapure deionization system and was used for all procedures unless otherwise stated. Fluorine-doped tin oxide (FTO) was purchased from Hartford Glass Company (7 $\Omega$ / $\square)$.

Solvothermal synthesis. FTO was chosen as a substrate as this is a fairly robust, transparent material that is also conductive. In general, $\mathrm{Fe}(\mathrm{acac})_{3}(1 \mathrm{mmol})$ is dissolved in 10.5 $\mathrm{mL}$ of absolute ethanol and a variable amount of deionized water and sonicated for 10 minutes. FTO substrates, cut into $3 \times 1 \mathrm{~cm}$ rectangles, were cleaned by ten-minute sonication in 
soapy water, deionized water, and isopropanol, in that order, and dried with $\mathrm{N}_{2}$ gas. These substrates were then subjected to a 15-min ozone plasma treatment to remove any trace organics. The clean, dry FTO substrates were then sealed inside a 25-mL Teflon-lined autoclave with the ethanol-based precursor solution and then heated to $180{ }^{\circ} \mathrm{C}$, for a given amount of time, 24 hours being the optimal reaction time. After naturally cooling to room temperature, the autoclave was opened, and the coated substrates were annealed in a tube furnace in air at $700{ }^{\circ} \mathrm{C}$ for 30 minutes.

Sn Doping. Tin-doped hematite films were prepared using the same synthetic procedures as described above, while using $\mathrm{Sn}(\mathrm{acac})_{2}$ as a co-precursor. Amounts ranging from 19 atomic percent (expressed herein as $\mathrm{Sn} / \mathrm{Fe}$ molar ratios) were added to the precursor solution (Table S1). While samples were prepared with and without the presence of added water, presented samples were synthesized in the absence of any water. The autoclaves were heated to $180{ }^{\circ} \mathrm{C}$ for periods ranging from 1 to 24 hours, with 6 hours being the optimal time. Coated substrates were annealed in a tube furnace in air at $700{ }^{\circ} \mathrm{C}$ for 30 minutes.

Electrochemistry. A CH Instrument Workstation 660D potentiostat was used for all electrochemical measurements. A Pt counterelectrode and a $\mathrm{Ag} / \mathrm{AgCl}$ (saturated $\mathrm{KCl}$ ) reference electrode were used. All measurements were done in 0.1 $\mathrm{M} \mathrm{NaOH}$ supporting electrolyte $(\mathrm{pH}=13)$. Electrochemical measurements were also made using anodic sweeps in order to assess the photoresponse of the hematite thin films (sweep rate is $100 \mathrm{mV} \mathrm{s}^{-1}$ unless stated otherwise). Performing multiple sweeps also allowed for the assessment of the durability of these films under applied voltage.

Electrochemical measurements under simulated solar radiation were made using a Newport solar simulator (150-W Xe arc lamp filtered through an AM 1.5 G air-mass filter) whose power output was measured to $1 \mathrm{Sun}\left(1.5 \mathrm{AM}, 100 \mathrm{~mW} / \mathrm{cm}^{2}\right)$ using a certified Si reference cell. The setup was equipped with a shutter, allowing for measurements to be made with switching between light and dark during chronoamperometric measurements, holding the applied voltage constant. For these measurements, a total time of 180 seconds was used, with switching between light and dark every 20 seconds.

All electrochemical measurements were performed three times: once in darkness, once with the light hitting the film directly (front illumination) and once with the light hitting the non-coated side of the FTO (backside illumination). All potentials are reported against the reversible hydrogen electrode:

$$
E_{\mathrm{RHE}}=E_{\mathrm{Ag} / \mathrm{AgCl}}+0.059 \mathrm{~V} \times \mathrm{pH}+E_{\mathrm{Ag} / \mathrm{AgCl}}^{\circ} .
$$

SEM imaging and EDXS measurements. Scanning electron microscopy (SEM) was performed with a Zeiss $\Sigma$ igmaVP field-emission SEM equipped with an Oxford INCA energydispersive X-ray spectroscopy (EDXS) unit. Particle sizes within the films were evaluated using the ImageJ software, ${ }^{28}$ with 300 particles being sized in each sample image. To obtain cross-section images, the FTO substrates coated with $\alpha$ $\mathrm{Fe}_{2} \mathrm{O}_{3}$ were cleaved in two and the freshly broken edges were imaged.

Diffuse reflectance measurements. Diffuse reflectance spectra were acquired using a Varian Cary 5000 UV-visible spectrophotometer equipped with a diffuse reflectance accessory (DRA-2500). Details of how this data was analysed can be found in the Supporting Information.

PXRD measurements. Powder x-ray diffraction measurements were made using a Rigaku Miniflex II bench-top diffractometer equipped with a $\mathrm{Cu} \mathrm{K} \alpha$ x-ray source $(\lambda=$ $1.5406 \AA$ ). Patterns were acquired at a rate of $0.02 \% \mathrm{~min}$.

Orange II azo-dye experiment. To assess the real surface areas of the synthesizsed photoanodes, we adapted Grätzel's orange azo-dye experiment. ${ }^{16}$ Briefly, the photoanode is soaked in a 1.5-mM solution of Orange II dye (in $\mathrm{H}_{2} \mathrm{O}$, $\mathrm{pH}$ adjusted to $3.5 \mathrm{using} \mathrm{HCl}$ ) for 15 minutes. After 15 minutes, the films are rinsed with dilute $\mathrm{HCl}(\mathrm{pH}=3.5)$ to remove any unbound dye molecules. The dye adsorbed to the surface is then desorbed with $0.5 \mathrm{~mL} 1.0 \mathrm{M} \mathrm{NaOH}$ and the optical density at $450 \mathrm{~nm}$ measured using UV-visible spectroscopy $\left(\varepsilon_{450 \mathrm{~nm}}=1.3 \times 10^{6} \mathrm{M}^{-1} \mathrm{~m}^{-1}\right)$. A standard curve was prepared (Fig. S10) in order to assess the concentration of dye resulting from soaking each sample. The molecular footprint of each dye molecule is $0.40 \mathrm{~nm}^{2} ;^{29}$ it is assumed a monolayer of dye is formed on the electrode's surface.

\section{RESULTS AND DISCUSSIONS}

\section{$\alpha-\mathrm{Fe}_{2} \mathrm{O}_{3}$ thin film characterization}

Nanocrystalline $\alpha-\mathrm{Fe}_{2} \mathrm{O}_{3}$ thin films on transparent and conductive fluorine-doped tin oxide (FTO) substrates were synthesized using a solvothermal approach, summarised here in Scheme 1.

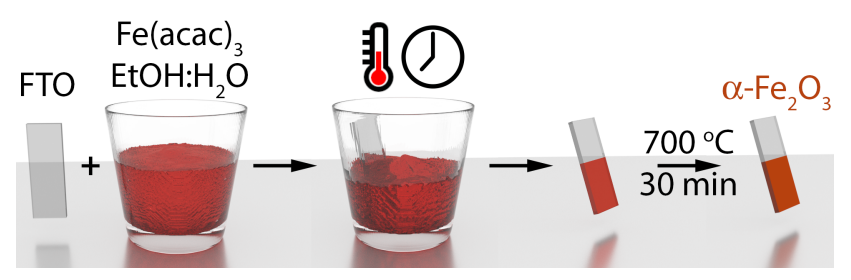

Scheme 1. Synthesis of nanostructured $\alpha-\mathrm{Fe}_{2} \mathrm{O}_{3}$ thin films on FTO substrates. Ratio of ethanol-to-water, reaction temperature, and reaction times were varied. The intermediate films are annealed in air at $700{ }^{\circ} \mathrm{C}$ for 30 minutes to obtain nanostructured $\alpha-\mathrm{Fe}_{2} \mathrm{O}_{3}$ thin films. Teflon liner is shown as transparent for clarity.

wherein we experimented with the addition of microliter-scale amounts of water to the $\mathrm{Fe}(\mathrm{acac})_{3} / \mathrm{EtOH}$ precursor solution to control nanocrystal size. Various parameters such as $\mathrm{Fe}(\mathrm{acac})_{3}$ concentration, solvothermal reactor temperature $\left(T_{\text {solvo }}\right)$, reaction time $\left(t_{\text {solvo }}\right)$ and annealing conditions $\left(T_{\text {anneal }}, t_{\text {anneal }}\right)$ were optimized. We settled on a reaction time of $24 \mathrm{~h}$ at $180{ }^{\circ} \mathrm{C}$ followed by annealing for 30 minutes at $700{ }^{\circ} \mathrm{C}$ in air, and these are the conditions used in this report unless otherwise stated. Under these conditions, we consistently obtained substrates coated with a uniform hematite film covering exclusively the FTO-coated side (Fig. 1). Visually, films produced with $100 \mu \mathrm{L} \mathrm{H}_{2} \mathrm{O}$ appeared the most opaque 


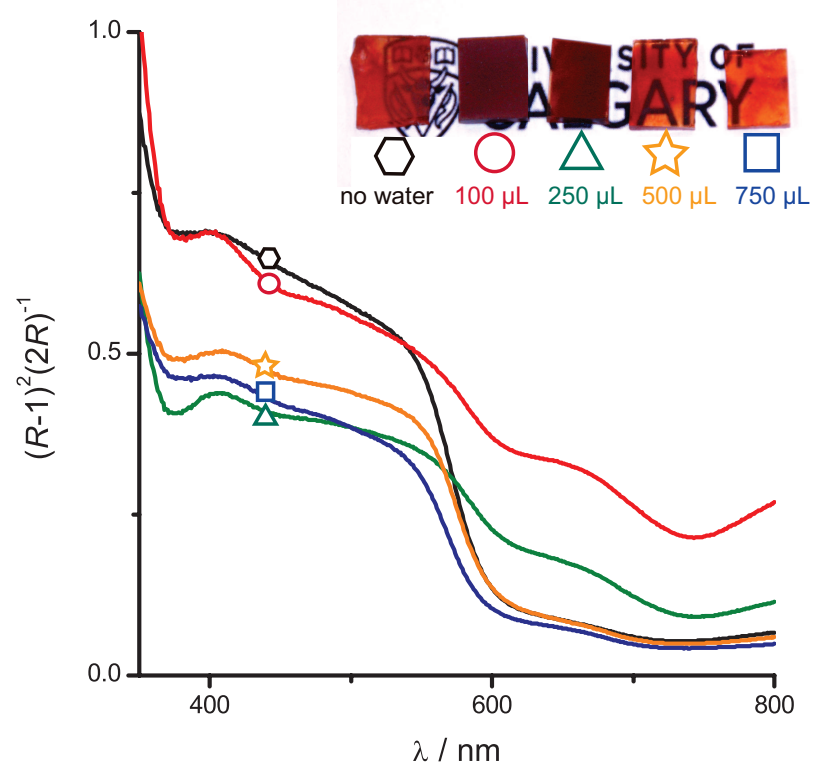

FIG. 1. Kubelka-Munk functions of $\alpha-\mathrm{Fe}_{2} \mathrm{O}_{3}$ thin films prepared on FTO with varying amounts of water. All samples were prepared under solvothermal conditions at $180^{\circ} \mathrm{C}$ for $24 \mathrm{~h}$, followed by a $30-$ min anneal at $700{ }^{\circ} \mathrm{C}$ in air.

and uniform among the series of films synthesized with different volumes of water added, as shown in the inset of Fig. 1. This observation was supported by absorbance measurements, which showed that of the films synthesised with water, the 100 $\mu \mathrm{L} \mathrm{H}_{2} \mathrm{O}$ sample absorbed the most light (Fig. 1). All of these films were found to be stable in aqueous solutions and under applied voltage (vide infra). When formed in the absence of water, the resulting films were thin and uneven, and were found to flake off of the substrate during electrochemical testing, demonstrating the importance of even small amounts of water.

Powder X-ray diffraction (PXRD, Fig. 2) was used to identify that after the initial solvothermal reaction, the product mainly consists of hematite, concomitantly with an impurity. Upon annealing at $700{ }^{\circ} \mathrm{C}$ in air for 30 minutes, only reflections due to hematite are visible in the powder pattern. Crosssectional scanning electron microscopy (SEM) revealed that hematite thin films made using this method average $c a .535$ $\mathrm{nm}$ in thickness (Fig. S1) which is desirable for the complete absorption of incoming light. ${ }^{30}$ EDXS confirmed only iron and oxygen were present within these samples in the expected 2:3 Fe:O ratio, consistent with hematite as the product.

SEM imaging of the films produced using this solvothermal method revealed highly structured and porous materials (Fig. 3). The observed films are reminiscent of hematite photoanodes formed through a solution-based colloidal method. ${ }^{31}$ We find that changing the water concentration significantly affected particle size, with the largest particles (mean diameter $=89 \mathrm{~nm}$ ) being attributed to the sample synthesized with the least amount of water $(100 \mu \mathrm{L}, c . f$. Fig. 3). The particle sizes were found to be inversely correlated to the amount of water added, with the smaller mean particle size of $61 \mathrm{~nm}$ observed in the sample synthesised with the largest amount of water

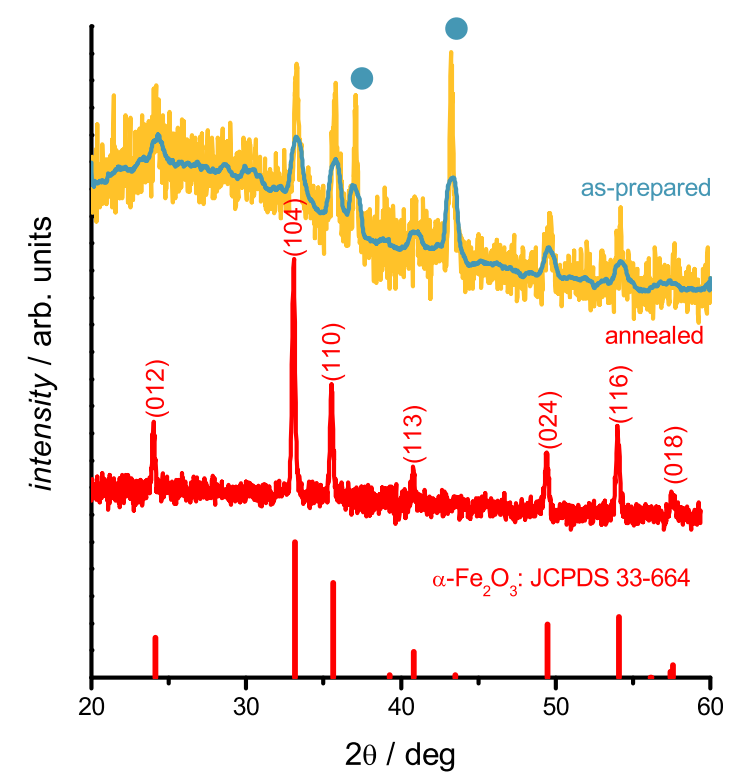

FIG. 2. Powder X-ray diffractogram of obtained thin films on FTO before and after annealing. Blue circles indicate peaks not attributed to hematite, and the line shows smoothed data.

used here, $750 \mu \mathrm{L}$ of $\mathrm{H}_{2} \mathrm{O}$. Attempts to form films with 10 $\mu \mathrm{L}$ and $50 \mu \mathrm{L}$ of added water did not produce films on the FTO substrates. As shown in Fig. 3, the size distributions of the films' constituent particles narrows with the volume of water added. These findings lead us to believe that the water participates in the nucleation of hematite nanocrystals by hydrolysing $\mathrm{Fe}(\mathrm{acac})_{3}$, as was previously proposed by Cai and colleagues, who suggested that an iron hydroxide could constitute the nucleation site during the solvothermal synthesis of $\alpha-\mathrm{Fe}_{2} \mathrm{O}_{3}$ nanoplatelets. ${ }^{22}$

\section{Tin doping}

Doping of the thin films was achieved by adding $\mathrm{Sn}(\mathrm{acac})_{2}$ to the $\mathrm{Fe}(\mathrm{acac})_{3} / \mathrm{EtOH}$ precursor solution in varying proportions. The same synthetic procedures were followed as for the pure hematite films, with $100 \mu \mathrm{L}$ of water added to the precursor, as this produced the best pure hematite films. Sndoped $\alpha-\mathrm{Fe}_{2} \mathrm{O}_{3}$ films produced using this method were flaky and unstable towards aqueous solutions. This problem was rectified when water was omitted from the precursor solution, leading us to conclude that $\mathrm{Sn}(\mathrm{acac})_{2}$ is involved in a side reaction with the water, impeding film formation. Upon removing the water from the reaction, the films were uniform, stable in water and showed improved electrochemical results when compared to the pure hematite samples (vide infra). Samples of good uniformity and stability were produced after only 6 hours reaction time, allowing us to reduce reaction time from the 24 hours used for the pure hematite films. Further experiments revealed that reaction times under 6 hours were insufficient for film formation. Incorporation of tin into the films 


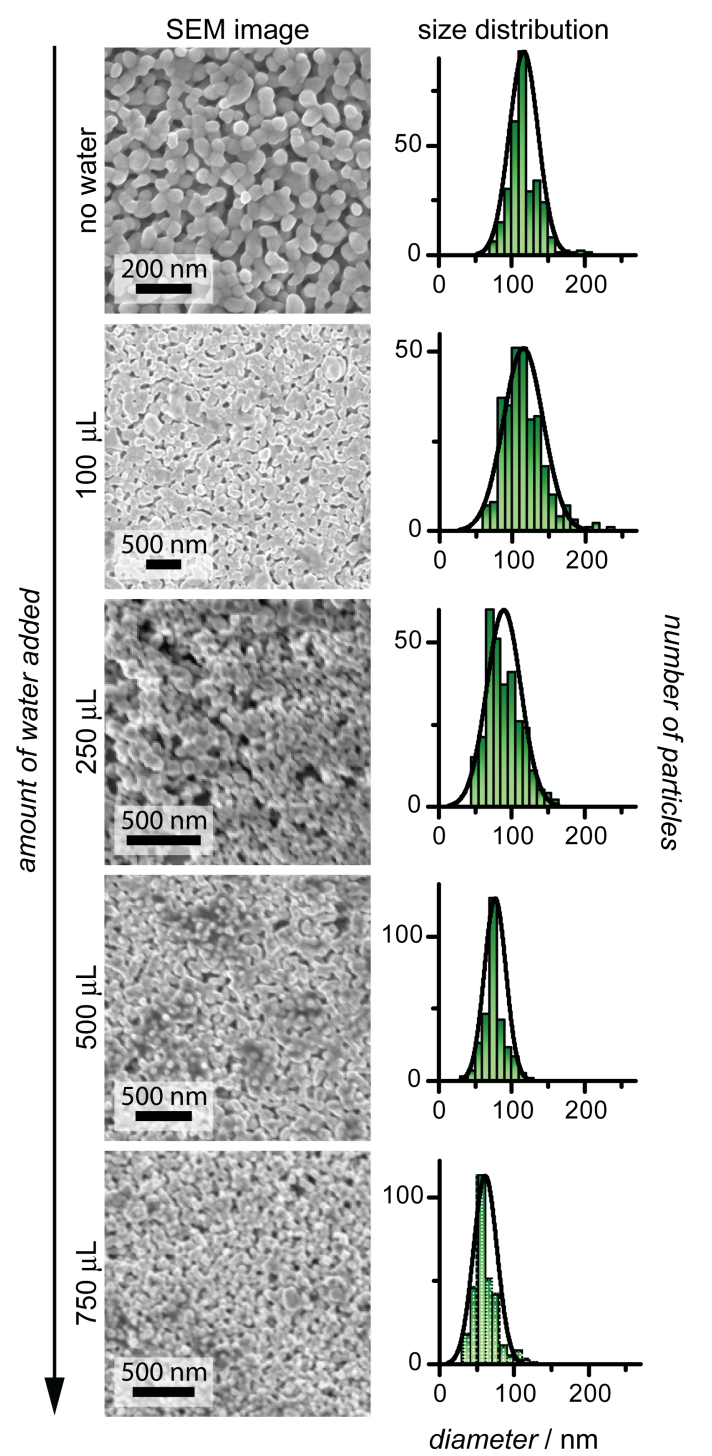

FIG. 3. Representative SEM images and corresponding size distributions for $\alpha-\mathrm{Fe}_{2} \mathrm{O}_{3}$ samples formed in the presence of various amounts of water. No water: Mean particle diameter $=116 \mathrm{~nm}, \sigma$ $=20 \mathrm{~nm} .100 \mu \mathrm{L} \mathrm{H} \mathrm{H}_{2} \mathrm{O}$ : Mean particle diameter $=115 \mathrm{~nm}, \sigma=27$ nm. $250 \mu \mathrm{L} \mathrm{H}_{2} \mathrm{O}$ : Mean particle diameter $=89 \mathrm{~nm}, \sigma=23 \mathrm{~nm} .500$ $\mu \mathrm{L} \mathrm{H}_{2} \mathrm{O}$ : Mean particle diameter $=77 \mathrm{~nm}, \sigma=15 \mathrm{~nm}$. $750 \mu \mathrm{L} \mathrm{H}_{2} \mathrm{O}$ : Mean particle diameter $=61 \mathrm{~nm}, \sigma=15 \mathrm{~nm} .300$ particles were sized for each sample.

was confirmed by EDXS. Tin observed by EDXS is not attributed to the FTO, as no trace of tin was found when the same method was used to probe samples of pure hematite.

Through SEM imaging, it was observed that the tin-doped series showed a similar trend to the water series in terms of the size distributions, indicating that $\mathrm{Sn}(\mathrm{acac})_{2}$ also acts as a nucleation promoter for this reaction. The tin-doped samples exhibited much larger particle sizes than the water series samples, as shown in Fig. 5. A larger size is associated with fewer nucleation sites. This is consistent with a larger amount of water $\left(100 \mu \mathrm{L}=5.5 \mathrm{mmol} \mathrm{H}_{2} \mathrm{O}\right)$ over the $0.08 \mathrm{mmol}$ of $\mathrm{Sn}(\mathrm{acac})_{2}$ used. The sizes of the particles could likely be fur-

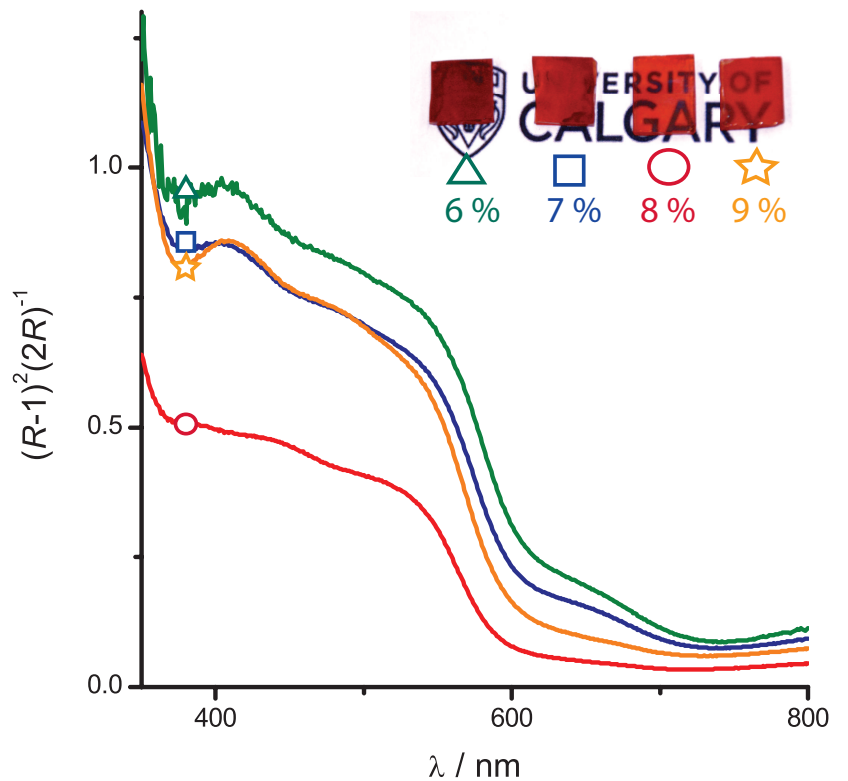

FIG. 4. Kubelka-Munk functions of $\alpha-\mathrm{Fe}_{2} \mathrm{O}_{3}$ samples prepared on FTO using varying amounts of $\mathrm{Sn}(\mathrm{acac})_{2}$ in the precursor solution. All samples were prepared using a $6 \mathrm{~h}$ reaction at $180^{\circ} \mathrm{C}$, followed by a 30 minute anneal at $700^{\circ} \mathrm{C}$ in air.

ther altered by finely adjusting the amount of tin used, thus allowing for enhanced tuning of the physical characteristics of the resulting films. The morphologies of the Sn-doped $\alpha-\mathrm{Fe}_{2} \mathrm{O}_{3}$ films also appear to differ from the pure hematite films, with the constituent particles within the films appearing more isolated from one another, in contrast to the fused particles seen in the pure $\alpha-\mathrm{Fe}_{2} \mathrm{O}_{3}$ samples. The surfaces of the Sn-doped particles also appeared more textured, suggesting a greater surface area.

\section{Optical band gaps of $\alpha-\mathrm{Fe}_{2} \mathrm{O}_{3}$ and $\mathrm{Sn}: \alpha-\mathrm{Fe}_{2} \mathrm{O}_{3}$}

The band gap of the materials synthesized by this method were investigated using a Tauc analysis of diffuse reflectance spectra (Fig. S2). The details of how the band gap energies were assessed and the associated Tauc plots can be found in the SI (Figs. S3-S4). Typically, hematite exhibits a direct band gap in the range of 1.95-2.35 eV and an indirect band gap of $1.38-2.09 \mathrm{eV}$, meaning that the primary band gap of hematite is an indirect, phonon-assisted band gap. ${ }^{32}$ The pure hematite samples exhibited a direct band gap of $c a .2 .07 \mathrm{eV}$ and an indirect band gap of $c a .1 .73 \mathrm{eV}$; the Sn-doped samples showed a direct band gap of $c a .2 .09 \mathrm{eV}$ and indirect band gap of $c a$. $1.80 \mathrm{eV}$. These band gaps are within the expected ranges for the direct and indirect band gaps of hematite.

\section{Photoelectrochemical water splitting by pristine and doped $\alpha-\mathrm{Fe}_{2} \mathrm{O}_{3}$ photoanodes}

To demonstrate the utility of this simple solvothermal synthetic method, we applied the as-made films - without further 


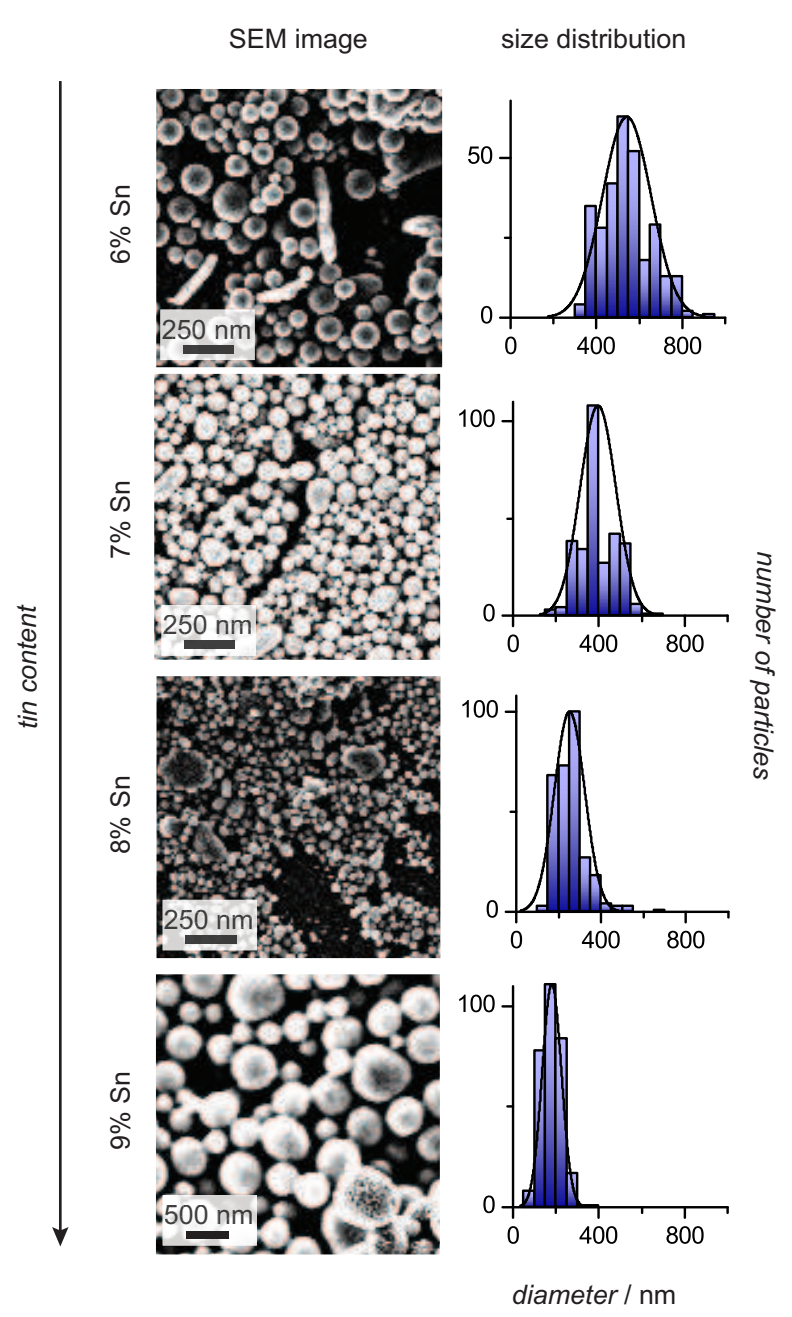

FIG. 5. Representative SEM images and corresponding size distribution data for tin series samples. $6 \% \mathrm{Sn}$ : Mean particle diameter $=$ $541 \mathrm{~nm}, \sigma=114 \mathrm{~nm} .7 \% \mathrm{Sn}$ : Mean particle diameter $=396 \mathrm{~nm}, \sigma$ $=84 \mathrm{~nm} .8 \%$ Sn: Mean particle diameter $=251 \mathrm{~nm}, \sigma=72 \mathrm{~nm} .9$ $\%$ : Mean particle diameter $=181 \mathrm{~nm}, \sigma=45 \mathrm{~nm}$. 300 particles were sized for each sample.

optimization - in prototype photoechemical cells. While the results are at this stage modest, they serve as a proof of concept for the method. Further optimization will be the focus of future work.

Electrochemical testing was performed in darkness and under 1-Sun illumination to assess the photoelectrochemical properties of $\alpha-\mathrm{Fe}_{2} \mathrm{O}_{3}$ thin films and determine how the different film morphologies affect photocatalytic properties. At an applied potential of $E_{\mathrm{RHE}}=1.5 \mathrm{~V}$ and in the dark, watersplitting is not observed for all electrodes presented here; rather, the onset of the catalytic wave is around $1.6 \mathrm{~V}$ vs RHE as seen in anodic scans performed in the dark (Fig. S5). However, upon irradiation a sharp rise in current density, and hence the rate of water oxydation, occurs (Fig. 6); this observation is again corroborated by an anodic current at $1.5 \mathrm{~V}$ vs RHE in the presence of light (Fig. S5). Chromoamperometric testing under chopped illumination $\left(E_{\mathrm{RHE}}=1.5 \mathrm{~V}, 20-\mathrm{s}\right.$

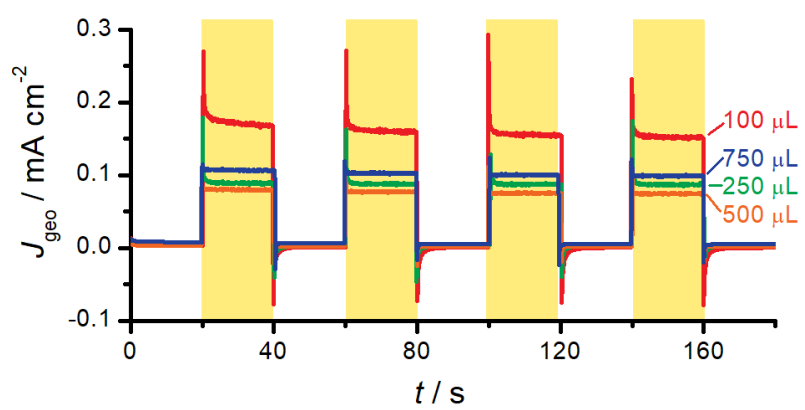

FIG. 6. Chronoamperometry results for samples made with different volumes of water added to the precusor solutions. All measurements were performed at a voltage of $1.5 \mathrm{~V}$ versus RHE.

chopping) identifies the sample made with $100 \mu \mathrm{L} \mathrm{H}_{2} \mathrm{O}$ as the most performant among the tested samples, achieving a maximum photocurrent density of $0.18 \mathrm{~mA} \mathrm{~cm}^{-2}$ when irradiated. The sample prepared with $100 \mu \mathrm{L}$ exhibits the largest individual particles within the films, meaning fewer grain boundaries were likely present in these samples. A lower number of grain boundaries likely enhances the electrical conductivity of these films, however we will discuss below that the increased surface are likely provides a better explanation for the superior performance of the $100 \mu \mathrm{L}$ samples compared to the other water series samples.

From Fig. 6, it is clear that these pure hematite films exhibit the typical "spike and overshoot" photocurrent pattern observed in films that display capacitive discharge. ${ }^{33}$ This pattern, where a large spike of current is seen immediately upon illumination (the instantaneous photocurrent) and then falls off rapidly, is typical for materials where holes recombine quickly with electrons at the surface. The instantaneous current indicates the separation of electrons and holes, but does not represent charge transfer across the interface. ${ }^{33}$ In contrast, the flat portion of the curve that follows represents the steady-state photocurrent, representing the holes that successfully interact with the electrolyte without recombination. Therefore, the ratio of the steady-state over the instantaneous photocurrent is indicative of the efficiency of charge separation in a material. ${ }^{33}$ As seen in Fig. 6, pure hematite photoanodes generated using this solvothermal method show a large degree of capacitance. This suggests that a significant amount of recombination occurs before the holes can interact with the water, leading to lower overall efficiency in these systems.

The real surface areas (as opposed to the geometric surface areas used in Fig. 6) of hematite films made in the presence of water were determined by the adsorption of the azodye Orange II, which forms a monolayer on nanocrystalline $\alpha-\mathrm{Fe}_{2} \mathrm{O}_{3} .{ }^{29}$ The results of these experiments are described in Fig. S6. In essence, the sample prepared with $100 \mu \mathrm{L}$ of $\mathrm{H}_{2} \mathrm{O}$ is found to have the largest real surface area relative to its geometric surface area, with a roughness factor of 23.1 (Fig. S6). This value is comparable to those reported by Grätzel and colleagues for their "cauliflower"-structured hematite thin films prepared by $\mathrm{APCVD}^{16}$ and equates to approximately four times the real surface of any other sample in the set. This greater surface likely in great part contributes to the over- 
all superior performance (per geometric area) of the $100 \mu \mathrm{L}$ $\mathrm{H}_{2} \mathrm{O}$ sample (Fig. 6), as it suggests that the material is highly porous and structured, as is desirable for this application. In fact, when the chronoamperometry data for the pure hematite samples made with different amounts of water was normalized against the true surface areas, the trend in performance of the films was found to be significantly changed, with the 100 $\mu \mathrm{L} \mathrm{H}_{2} \mathrm{O}$ sample performing the worst per unit of area, despite that this sample achieved the highest overall current density of all the films made in the presence of water (Fig. S7). While it was argued that fewer grain boundaries were observed in the film prepared with $100 \mu \mathrm{L}$ of $\mathrm{H}_{2} \mathrm{O}$, the larger crystals make it more likely the photogenerated electron-hole pair will be further from the SCLJ. Films with smaller nanoparticles (i.e. more water added) thus present a higher activity based on real surface areas.

Through electrochemical testing, it was also found that backside illumination of the film generated a higher current density than shining the light directly on the coated side of the substrate for every sample tested (pure and doped). In fact, some films that showed no response at all to illumination from the front showed strong current densities when illuminated from the backside, as shown by anodic scans and chronoamperometric measurements (Figs. S5 and S8). This increased activity has been attributed to light being absorbed closer to the conductive FTO when light is directed from the back, meaning electron-hole pairs are generated closer to the conductive substrate. If the electron is excited closer to the substrate, this would lead to better conduction and thus higher efficiency, explaining in part why backside illumination gives superior results. Additionally, diffusion of tin from the FTO substrate into the $\alpha-\mathrm{Fe}_{2} \mathrm{O}_{3}$ film during the annealing step is also likely, as has been previously reported. ${ }^{34}$ This unintentional insertion of tin could lead to better charge separation and enhanced conduction close to the FTO surface, again leading to superior film performance when backside illumination is employed.

The improved photoactivity of $\alpha-\mathrm{Fe}_{2} \mathrm{O}_{3}$ films upon Sndoping was first noted by Sivula et al. ${ }^{31}$ who reported that high sintering temperatures caused diffusion of Sn from the FTO into their hematite photoanode materials. This unintentional doping led to a two-fold increase in film performance and was attributed to an improved absorption coefficient. ${ }^{31}$ Intentional doping of $\alpha-\mathrm{Fe}_{2} \mathrm{O}_{3}$ films with tin has shown the same improved performance, as demonstrated by Ling et al. ${ }^{34}$ who suggested that this improved performance is likely due to increased electrical conductivity from electron-donating $\mathrm{Sn}$. Dunn et al. also found that tin doping greatly improved hematite photoanode performance, but this group attributed the improvement to increased hole transfer at the surface, as shown by intensity-modulated photocurrent spectroscopy and chronoamperometry data. ${ }^{35}$ These findings, as well as tin's low cost and abundance, make tin a promising candidate for the doping of hematite films, as demonstrated here.

Samples prepared with $8 \%$ molar ratio of Sn yielded the best chronoamperometry results of all the compositions we attempted, with a photocurrent density of $0.40 \mathrm{~mA} \mathrm{~cm}-2$ (Fig. 7), doubling the best performance observed for the pure

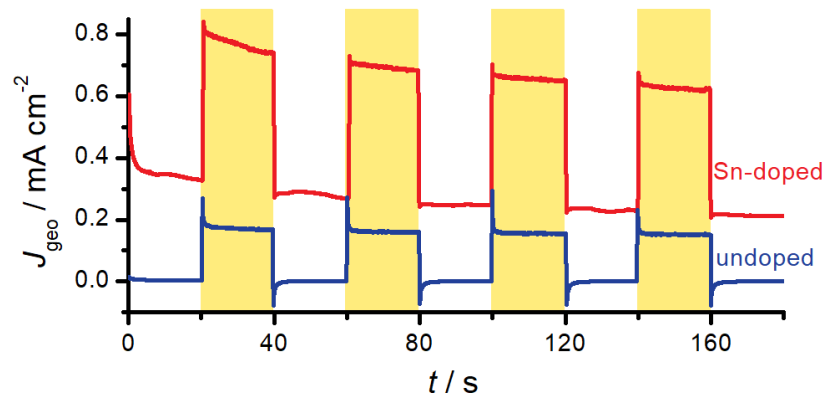

FIG. 7. Chronoamperometry results for sample made with $8 \% \mathrm{Sn}$ doping (red trace) compared with the best performing pure hematite film (blue trace). All measurements were performed at a voltage of $1.5 \mathrm{~V}$ versus RHE under backside illumination.

$\alpha-\mathrm{Fe}_{2} \mathrm{O}_{3}$ films. This sample was also the most durable in aqueous solutions and under applied voltage, with no visible deterioration occurring even after several electrochemical tests. The other tin doped samples became blackened during electrochemical testing and flaked off of the FTO substrate (Fig. S9), making it difficult to successfully assess their photoelectrochemical performance. It should also be noted that the chronoamperometry data of Fig. 4 shows a drastically reduced capacitative discharge upon illumination when compared to $\alpha-\mathrm{Fe}_{2} \mathrm{O}_{3}$ (Fig. 6), indicating that a smaller degree of surface electron-hole recombination is occurring, supporting the finding of Dunn and colleagues that tin doping might speed up hole transfer kinetics. ${ }^{35}$

\section{CONCLUSIONS}

In summary, the synthetic procedure we have devised here reliably produces hematite thin films with an average thickness of $c a .535 \mathrm{~nm}$. By varying the amount of water added to the precursor solution, it is possible to alter the size distribution of the film's particles, meaning that the morphology and resulting electrochemical properties can be tuned. Additionally, the same synthesis can be used to produce tin-doped films by incorporating $\mathrm{Sn}(\mathrm{acac})_{2}$ into the precursor solution, adding further customisability to these films and a means to further improve their performance. The simplicity and scalability of this procedure makes it an interesting new method for synthesising pure and doped hematite thin films.

\section{SUPPLEMENTARY DATA}

The Supplementary Data contains details of Tauc-Lorentz analysis, SEM images, details of surface area determination, and electrochemical characterization.

\section{Acknowledgements}

This work was supported by the Canada School of Energy and Environment (Proof-of-Concept Grant), the Natural Sci- 
ence and Engineering Research Council of Canada (Discovery Grant and USRA), the University of Calgary, and used instrumentation funded by the Canada Foundation for Innovation's John R. Evans Leaders Fund. O'Connell acknowledges the Trans-Atlantic Science Student Exchange Program. We thank B.S. Gelfand for assistance with XRD measurements and L. Bhandari for assistance with diffuse reflectance measurements.

\section{NOTES AND REFERENCES}

${ }^{1}$ M. M. Rahman, A. J. S. Ahammad, J.-H. Jin, S. J. Ahn and J.-J. Lee, Sensors, 2010, 10, 4855-4886.

${ }^{2}$ A. Shipway, M. Lahav and I. Willner, Adv. Mater, 2000, 12, 993-998.

${ }^{3}$ A. Yu, Z. Liang, J. Cho and F. Caruso, Nano Lett., 2003, 3, 1203-1207.

${ }^{4}$ Y.-G. Guo, J.-S. Hu and L.-J. Wan, Adv. Mater., 2008, 20, 2878-2887.

${ }^{5}$ P. Simon and Y. Gogotsi, Nat. Mater., 2008, 7, 845-854.

${ }^{6}$ J. Zhang and C. M. Li, Chem. Soc. Rev., 2012, 41, 7016-7031.

${ }^{7}$ T. Zhu, M. N. Chong and E. S. Chan, ChemSusChem, 2014, 7, 2974-2997.

${ }^{8}$ J. Lee, O. K. Farha, J. Roberts, K. A. Scheidt, S. T. Nguyen and J. T. Hupp, Chem. Soc. Rev., 2009, 38, 1450-1459.

${ }^{9}$ I. Hamley, Nanotechnology, 2003, 14, R39-R54.

${ }^{10}$ A. Stein and R. Schroden, Curr. Opin. Solid State Mater. Sci., 2001, 5, 553564.

${ }^{11}$ S. Kitagawa, R. Kitaura and S. Noro, Angew. Chem. Int. Ed., 2004, 43, 2334-2375.

${ }^{12}$ M. Eddaoudi, D. Moler, H. Li, B. Chen, T. Reineke, M. O'Keeffe and O. Yaghi, Acc. Chem. Res., 2001, 34, 319-330.

${ }^{13}$ K. Sivula, F. Le Formal and M. Grätzel, ChemSusChem, 2011, 4, 432-449.

${ }^{14}$ M. Grätzel, Nature, 2001, 414, 338-344.

${ }^{15}$ M. G. Walter, E. L. Warren, J. R. McKone, S. W. Boettcher, Q. Mi, E. A. Santori and N. S. Lewis, Chem. Rev., 2011, 111, 6446.

${ }^{16}$ A. Kay, I. Cesar and M. Grätzel, J. Am. Chem. Soc., 2006, 128, 15714 15721.

${ }^{17}$ C. D. Bohn, A. K. Agrawal, E. C. Walter, M. D. Vaudin, A. A. Herzing, P. M. Haney, A. A. Talin and V. A. Szalai, J. Phys. Chem. C, 2012, 116, 15290-15296.

${ }^{18}$ A. Kleiman-Shwarsctein, Y.-S. Hu, A. J. Forman, G. D. Stucky and E. W. McFarland, J. Phys. Chem. C, 2008, 112, 15900-15907.

${ }^{19}$ N. T. Hahn and C. B. Mullins, Chem. Mater, 2010, 22, 6474-6482.

${ }^{20}$ O. Zandi, B. M. Klahr and T. W. Hamann, Energy Environ. Sci., 2013, 6, 634-642.

${ }^{21}$ I. Herrmann-Geppert, P. Bogdanoff, J. Radnik, S. Fengler, T. Dittrich and S. Fiechter, Phys. Chem. Chem. Phys., 2013, 15, 1389-1398.

${ }^{22}$ J. Cai, S. Chen, M. Ji, J. Hu, Y. Ma and L. Qi, CrystEngComm, 2014, 16, 1553-1559.

${ }^{23}$ R. Walton, Chem. Soc. Rev., 2002, 31, 230-238.

${ }^{24}$ N. Pinna and M. Niederberger, Angew. Chem. Int. Ed., 2008, 47, 52925304.

${ }^{25}$ K. Sun, W. Wei, Y. Ding, Y. Jing, Z. L. Wang and D. Wang, Chem. Commun., 2011, 47, 7776-7778.

${ }^{26}$ V. Kondalkar, R. Kharade, S. Mali, R. Mane, P. Patil, P. Patil, S. Choudhury and P. Bhosale, Superlattices Microstruct., 2014, 73, 290 - 295.

${ }^{27}$ I. A. Velasco-Davalos, M. Moretti, M. Nicklaus, C. Nauenheim, S. Li, R. Nechache, C. Gomez-Yanez and A. Ruediger, Appl. Phys. A, 2014, 115, 1081-1085.

${ }^{28}$ C. A. Schneider, W. S. Rasband and K. W. Eliceiri, Nat. Methods, 2012, 9, 671-675.

${ }^{29}$ J. Bandara, J. A. Mielczarski and J. Kiwi, Langmuir, 1999, 15, 7670-7679.

${ }^{30}$ K. Itoh and J. O. Bockris, J. Electrochem. Soc., 1984, 131, 1266-1271.

${ }^{31}$ K. Sivula, R. Zboril, F. Le Formal, R. Robert, A. Weidenkaff, J. Tucek, J. Frydrych and M. Grätzel, J. Am. Chem. Soc., 2010, 132, 7436-7444.

${ }^{32}$ M. Al-Kuhaili, M. Saleem and S. Durrani, J. Alloys. Compd., 2012, 521, $178-182$.

${ }^{33}$ L. M. Peter, J. Solid State Electrochem., 2013, 17, 315-326.

${ }^{34}$ Y. Ling, G. Wang, D. A. Wheeler, J. Z. Zhang and Y. Li, Nano Lett., 2011, 11, 2119-2125.
${ }^{35}$ H. K. Dunn, J. M. Feckl, A. Muller, D. Fattakhova-Rohlfing, S. G. Morehead, J. Roos, L. M. Peter, C. Scheu and T. Bein, Phys. Chem. Chem. Phys., 2014, 16, 24610-24620. 


\title{
Electronic Supplementary Information: Simple solvothermal approach to highly nanostructured hematite thin films
}

\author{
Casey M. Platnich, ${ }^{a}$ Jachym S. Slabby, ${ }^{* a}$ David O'Connell, ${ }^{* a}$ and Simon Trudel ${ }^{* a}$ \\ ${ }^{a}$ Department of Chemistry and Institute for Quantum Science and Technology, University of Calgary, 2500 University Drive \\ NW, Calgary, AB, Canada, T2N 1N4; \\ E-mail: trudels@ucalgary.ca
}

DIFFUSE REFLECTANCE MEASUREMENTS AND ASSESSMENT OF BAND GAP ENERGIES

Diffuse reflectance measurements were made in order to assess the band gap energies of the materials we synthesized. Hematite has well-defined band gap $E_{\mathrm{g}}$ energies of 1.95-2.35 eV for the direct band gap and 1.38-2.09 for the indirect band gap. Using the Tauc relationship,

$$
\alpha h v \propto\left(h v-E_{\mathrm{g}}\right)^{n}
$$

It is possible to determine the band gap energy of a material based on the absorption of light. In this relationship, $\alpha$ denotes the absorption coefficient, $h v$ the energy of the photon, and $n$ is an exponent that takes into account the nature of the transition ( $n=\frac{1}{2}$ for direct allowed transitions, $n=2$ for indirect allowed transitions). Usually the absorption can be measured directly using UV-visible spectroscopy, but due to the opaque natures of our films, this was not possible. For this reason, we used diffuse reflectance to obtain the reflectance $R$ of our films, which we converted to transmittance $T$ using the formula:

$$
\frac{1}{T}=\frac{(1-R)^{2}}{2 R}
$$

This is then transformed to give $\alpha$ using the relationship:

$$
\alpha=-\frac{1}{d} \ln T
$$

Where $d$ is the film thickness. Here, we have assumed that all of the films had an average thickness of approximately $535 \mathrm{~nm}$. Once these values are obtained, the Tauc plots can be generated with the photon energy on the $x$-axis and $(\alpha h v)^{\frac{1}{n}}$ on the $y$-axis. An extrapolation of the longest linear region of the plot gives the value of the band gap as the horizontal axis intercept. 


\begin{tabular}{lcc}
\hline Sample & $\begin{array}{c}\text { Amount Sn(acac })_{2} \\
(\mathrm{~g} ; \text { mmol })\end{array}$ & $\begin{array}{c}\text { Amount Fe(acac })_{3} \\
(\mathrm{~g} ; \mathrm{mmol})\end{array}$ \\
\hline $6 \%$ & $0.0192 ; 0.06$ & $0.353 ; 1.00$ \\
$7 \%$ & $0.0224 ; 0.07$ & $0.353 ; 1.00$ \\
$8 \%$ & $0.0256 ; 0.08$ & $0.353 ; 1.00$ \\
$9 \%$ & $0.0288 ; 0.09$ & $0.353 ; 1.00$ \\
\hline
\end{tabular}

TABLE S1. Sn doping compositions

\section{FIGURES}

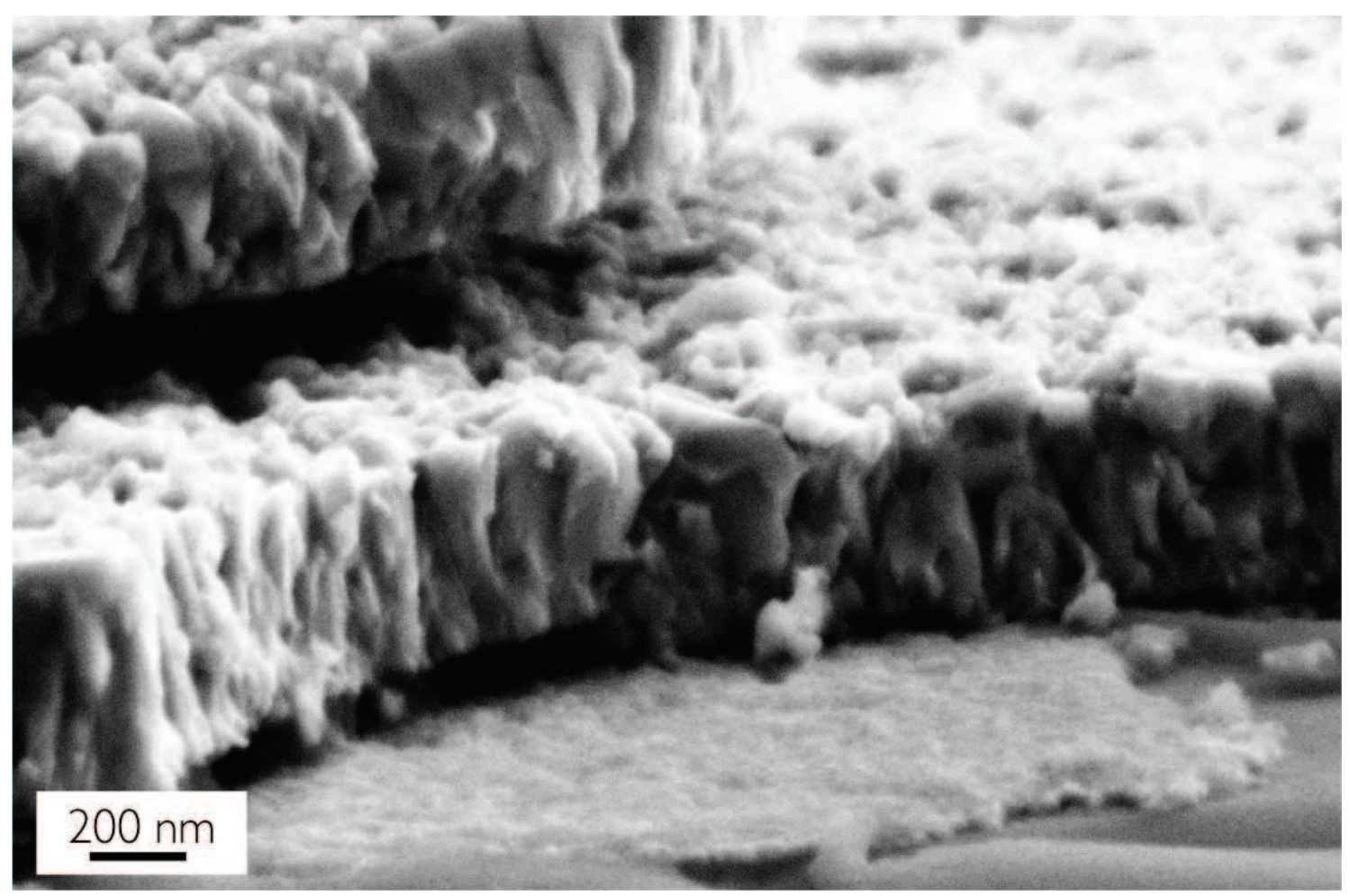

FIG. S1. Cross-sectional SEM image of pure hematite sample synthesized with $100 \mu \mathrm{L} \mathrm{H}_{2} \mathrm{O}$. 


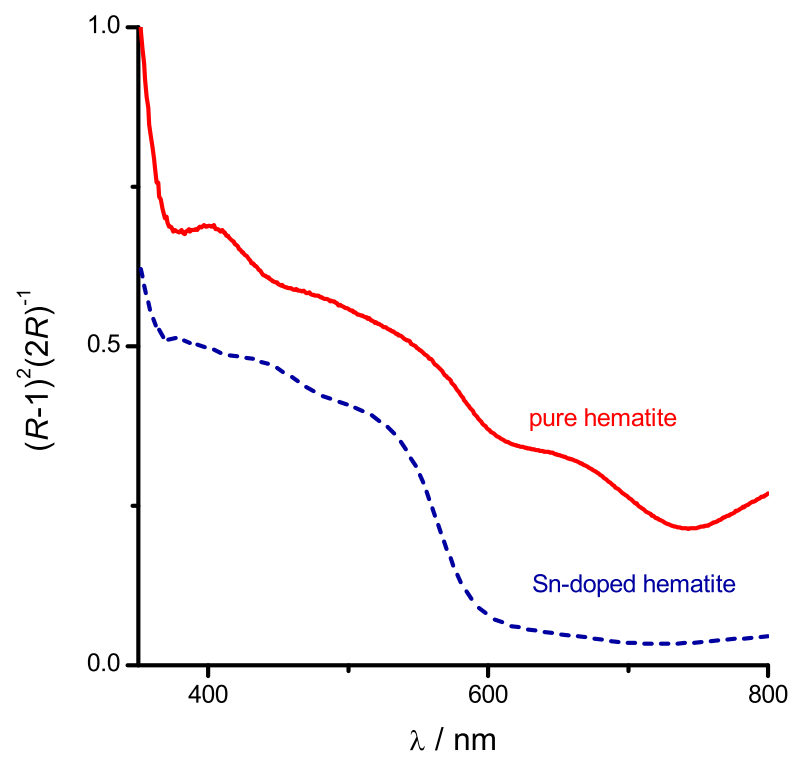

FIG. S2. Kubelka-Munk functions of pure $\alpha-\mathrm{Fe}_{2} \mathrm{O}_{3}$ thin film and $8 \%$ Sn-doped $\alpha-\mathrm{Fe}_{2} \mathrm{O}_{3}$ film.
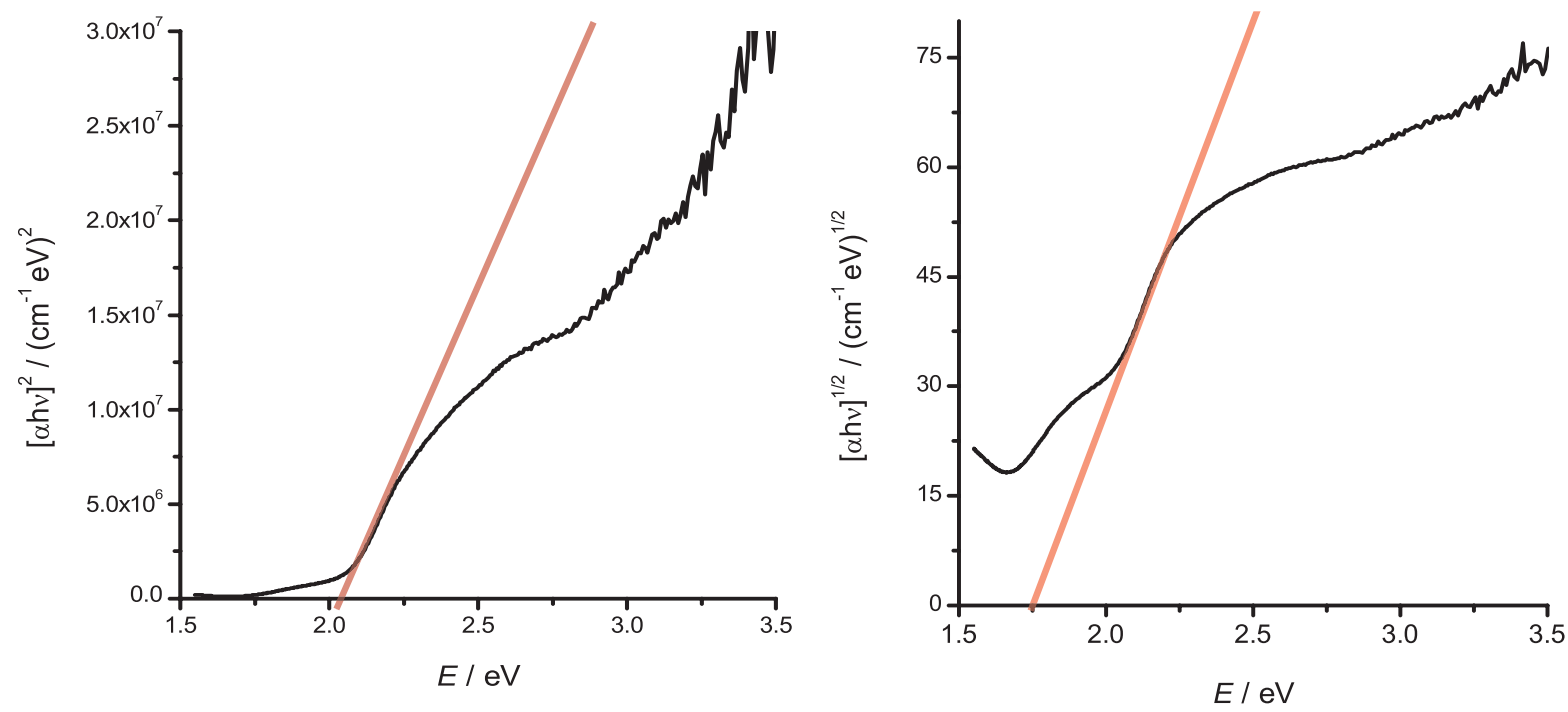

FIG. S3. Tauc plots of direct band gap (left) and indirect band gap (right) for pure hematite sample synthesized with $100 \mu \mathrm{L} \mathrm{H}_{2} \mathrm{O}$. The direct band gap energy is estimated to be $c a$. $2.04 \mathrm{eV}$, while the indirect band gap energy is approximately $1.74 \mathrm{eV}$. These values are within the accepted range for hematite. 

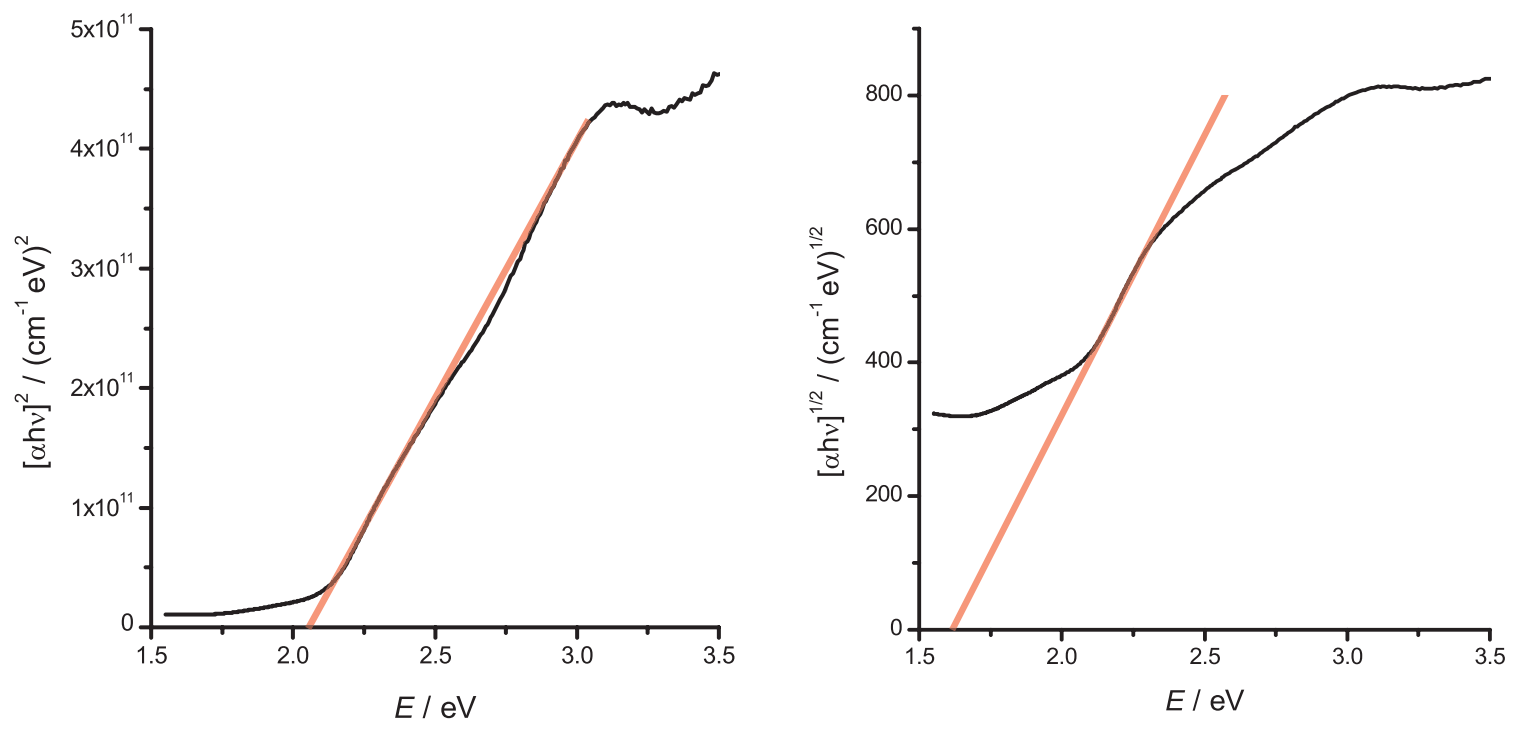

FIG. S4. Tauc plots of direct band gap (left) and indirect band gap (right) for 7\% Sn-doped hematite sample. The band gap energies are estimated to be $c a .2 .04 \mathrm{eV}$ and $1.63 \mathrm{eV}$ for the direct and indirect band gaps, respectively. These values are within the accepted range for hematite.

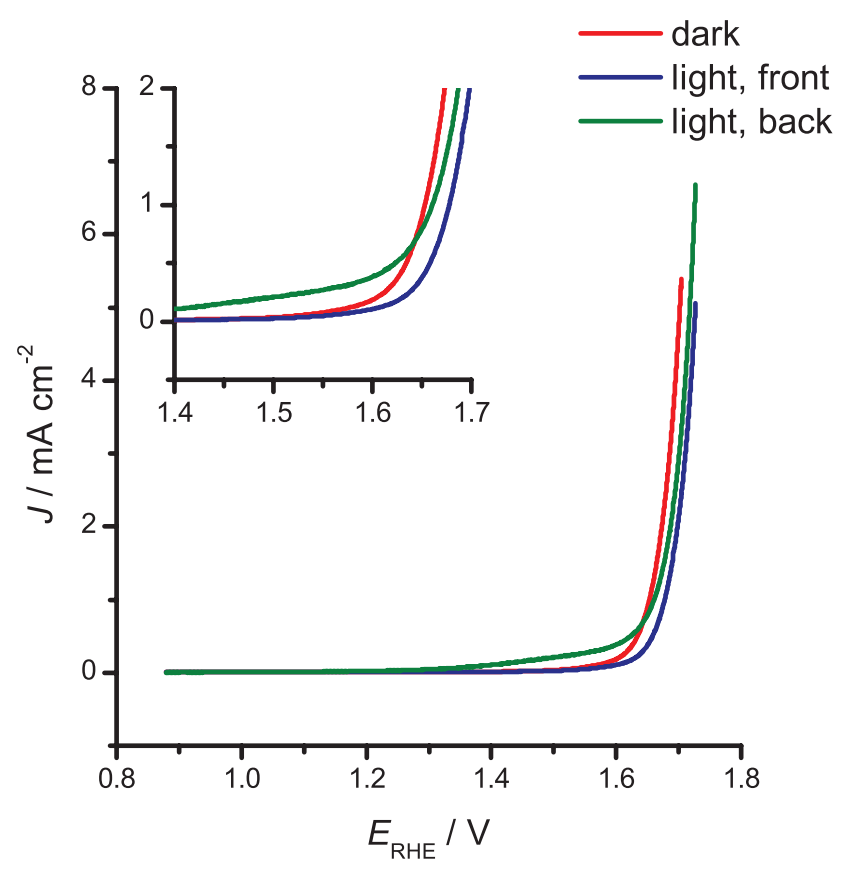

FIG. S5. Anodic scan of pure hematite sample synthesized with $100 \mu \mathrm{L} \mathrm{H} \mathrm{H}_{2} \mathrm{O}$. Inset: zoom of onset region, showing enhanced performance with backside illumination. 


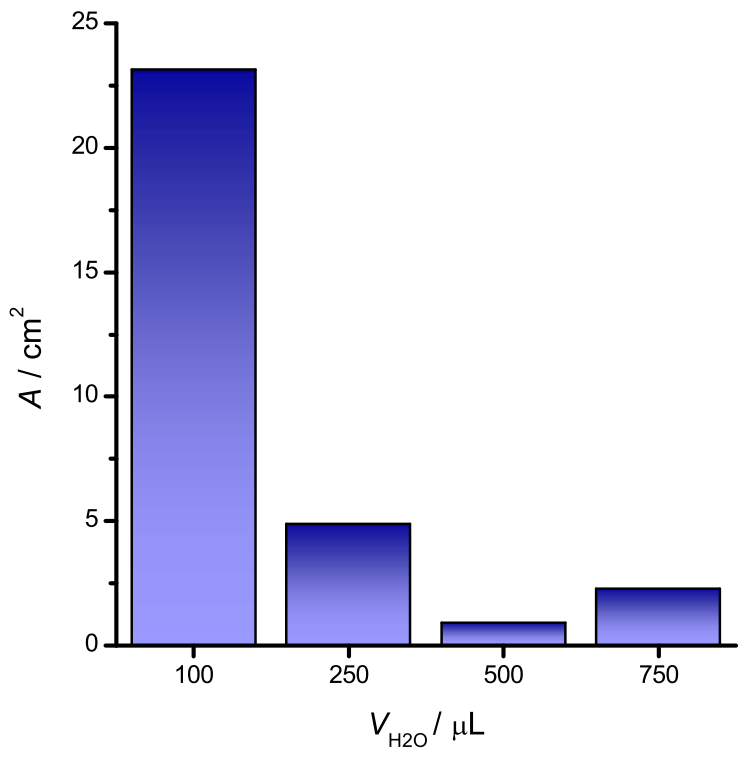

FIG. S6. Real surface area (per $1.0 \mathrm{~cm}^{2}$ of geometric surface area) for samples prepared with various amounts of water. These values are equivalent to often-reported "roughness factors" of the samples.

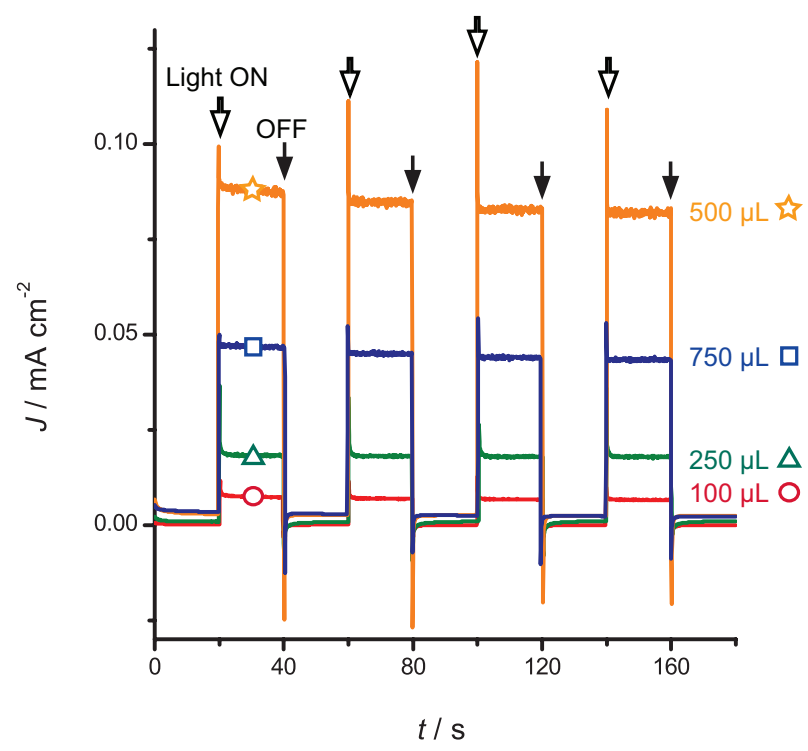

FIG. S7. Chronoamperometry of pure hematite films normalized to their real surface areas as determined by the Orange II azo-dye experiment. 


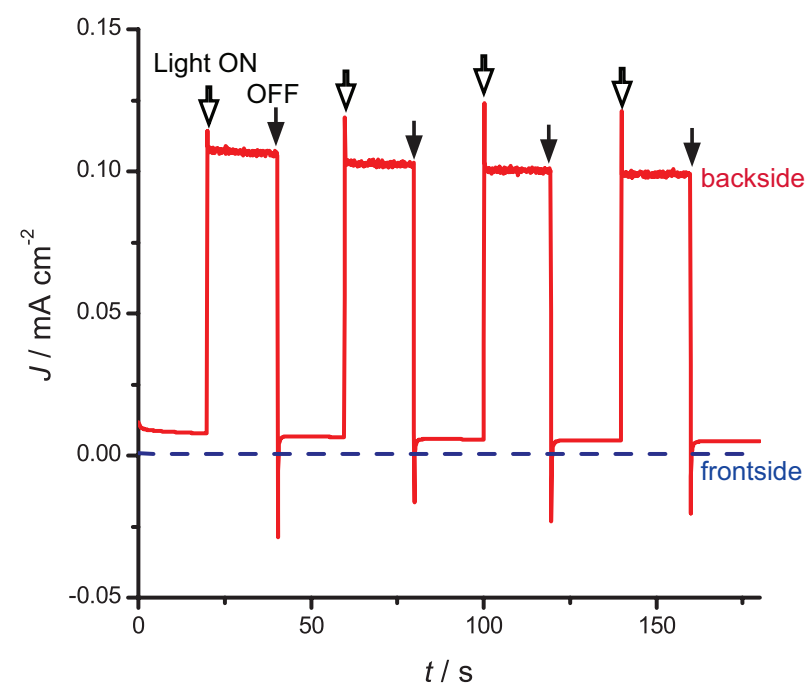

FIG. S8. Chronoamperometry of pure hematite sample synthesized with $750 \mu \mathrm{L} \mathrm{H}_{2} \mathrm{O}$, showing the difference in response between illumination from the front (blue trace) and from the back (red trace).

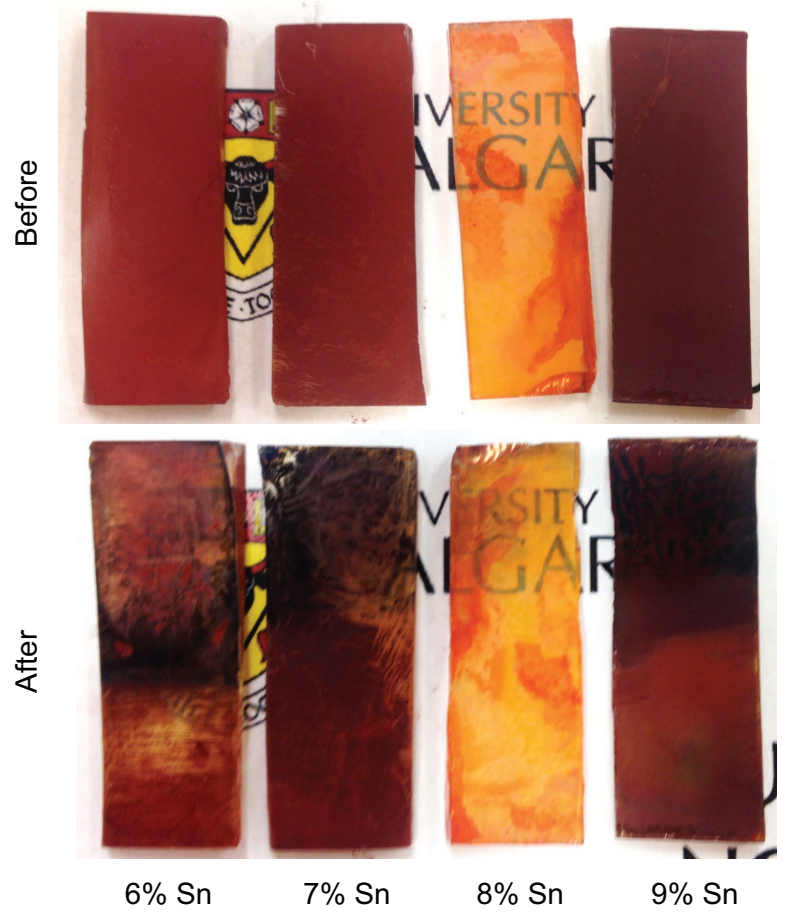

FIG. S9. Photos of Sn-doped hematite films before and after electrochemical testing. 


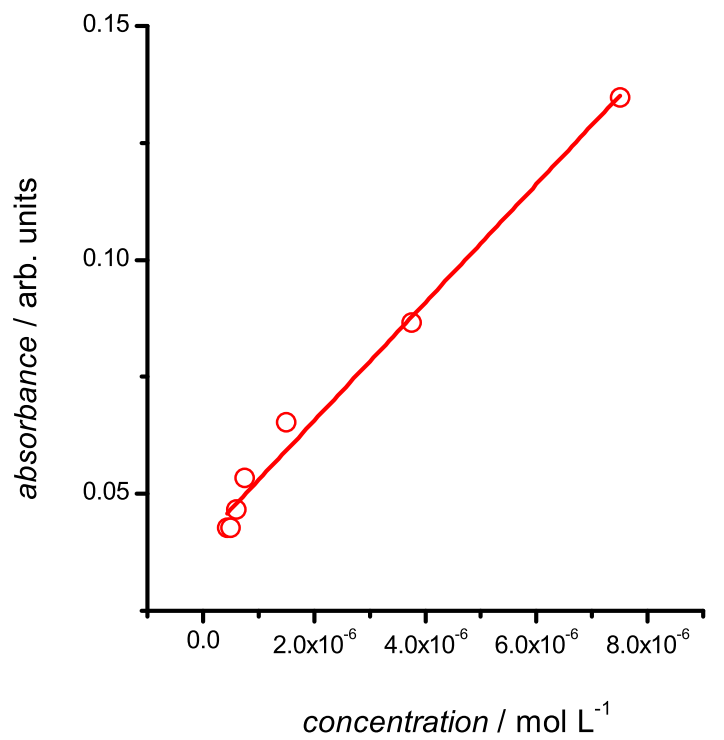

FIG. S10. Standard curve for Orange II azo-dye experiment. 